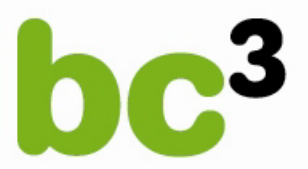

BASQUE CENTRE

FOR CLIMATE CHANGE

Klima Aldaketa Ikergai

\title{
ICT Applications in the Research for Environmental Sustainability
}

Aline Chiabai, Dirk Rübbelke and Lisa Maurer

November 2010

BC3 WORKING PAPER SERIES

2010-18 
The Basque Centre for Climate Change (BC3) is a Research Centre based in the Basque Country, which aims at contributing to long-term research on the causes and consequences of Climate Change in order to foster the creation of knowledge in this multidisciplinary science.

The BC3 promotes a highly-qualified team of researchers with the primary objective of achieving excellence in research, training and dissemination. The Scientific Plan of BC3 is led by the Scientific Director, Prof. Anil Markandya.

The core research avenues are:

- $\quad$ Adaptation to and the impacts of climate change

- $\quad$ Measures to mitigate the amount of climate change experienced

- $\quad$ International Dimensions of Climate Policy

- $\quad$ Developing and supporting research that informs climate policy in the Basque Country

See www.bc3research.org for further details.

The BC3 Working Paper Series is available on the internet at http://www.bc3research.org/working_papers/view.html

Enquiries (Regarding the BC3 Working Paper Series):

Roger Fouquet

Email: roger.fouquet@bc3research.org

The opinions expressed in this working paper do not necessarily reflect the position of Basque Centre for Climate Change (BC3) as a whole.

Note: If printed, please remember to print on both sides. Also, perhaps try two pages on one side. 


\title{
ICT Applications in the Research for Environmental Sustainability
}

\author{
Aline Chiabai ${ }^{*}$, Dirk Rübbelke ${ }^{* *}$ and Lisa Maurer ${ }^{* * *}$
}

\begin{abstract}
Whether Information and Communication Technology (ICT) constitutes a threat or a cure to environment's deterioration is controversially discussed. Empirical evidence on the impacts of ICT is rare, so that generalisable lessons can be drawn is sparse. This study addresses exactly this critique by providing empirical results on the role of ICT in research for environmental sustainability. Application of ICT in research is generally regarded as a way to exploit such technology in favour of the environment. Our analysis shows that the use of ICT in environmental research is of great importance in the scientific community, but it can also play a crucial role in the policy context, as well as in the business sector.
\end{abstract}

Keywords: Information and Communication Technology (ICT), biodiversity, climate change, energy efficiency, environmental research, natural resources, sustainability.

JEL classifications: Q01, Q54, Q57, I20

Cite as: Chiabai, A., Rübbelke, D. and Maurer, L. (2010), ICT Application in the Research for Environmental Sustainability. BC3 Working Paper Series 2010-18. Basque Centre for Climate Change (BC3). Bilbao, Spain.

* Corresponding author. Basque Centre for Climate Change (BC3), Spain, e-mail: aline.chiabai@bc3research.org;

** Basque Centre for Climate Change (BC3) and Ikerbasque, Basque Foundations for Science, Spain, e-mail: dirk.ruebbelke@bc3research.org;

*** Knowledge Management Institute, Graz University of Technology, Austria, e-mail: lisa.maurer@tugraz.at 


\section{INTRODUCTION}

The impact of human activity on the global ecological systems has become excessively severe such that it endangers the means of livelihood for future generations. Sciences can help to address the most pressing problems on our planet like climate change, biodiversity loss, ebbing of natural resources and the lack in energy security by providing more comprehensive information about and understanding of processes and systems as well as by developing technologies for society helping to return to a sustainable path. As Lubchenco (1998: 491) points out: "New fundamental research, faster and more effective transmission of new and existing knowledge to policy- and decision-makers, and better communication of this knowledge to the public will all be required to meet this challenge.”

New Information and Communication Technologies (ICT) may represent appropriate tools to support environmental research and its transmission to policy-makers and the general public. ${ }^{1}$ According to Esty (2004: 117), “[i]nformation issues are central to the challenge of environmental protection." However, the influence of ICT on sustainable development of human society is still not well understood and strongly disputed. On the one hand, ICT effects seem to be positive because it is often seen to improve the use of matters and energy. Berkhout and Hertin (2001: 4-5) distinguish between first to third order positive effects. They regard "ICT for environmental protection purposes” as a first order positive effect, while "dematerialisation and structural change" and "life style changes" are considered to be second and third order positive effects respectively. On the other hand, there are also negative effects of ICTs, which Berkhout and Hertin (2001: 4-5) distinguish also by their order: "environmental impacts of production and use of ICTs", “incomplete substitution" and "rebound effects" are the first, second and third order negative effects of ICTs respectively. In their review of research on the environmental impact of e-business and ICT, Yi and Thomas (2007: 847) point out that the distinction of three different order effects of ICT is the most quoted categorisation in this research field and they consider this categorisation to be "a promising route to take the research forward.”

As Berkhout and Hertin (2001: 6) stress, the potential impacts of ICT are "matched by uncertainty whether they will be realised" and "[g]ood empirical evidence from which generalised lessons can be drawn is sparse.” Our study addresses exactly this critique by

\footnotetext{
${ }^{1}$ See Arnold, de Lange and Blind (2005) for a description of a concerted action aiming at bridging the gap between research and EU Water Framework Directive implementation amongst others by using ICT tools.
} 
providing empirical evidence on the realisation of positive impacts of ICTs on the environment. In doing so we focus on the first - and partly second - order positive impacts, or put it more specifically, we investigate to which extent and in which way ICTs are employed in environmental research as tools to support and develop sustainable strategies. Of course, in doing so we implicitly also touch third order aspects in our analysis, since life style changes are regularly in the researchers' range of vision. In our empirical study we focus on four key environmental research sectors: climate change, biodiversity, energy efficiency and natural resources.

Application of ICT might indeed have significant productivity effects, ${ }^{2}$ as Hempell (2005) shows in an analysis of German service firms. Yet, a strong diffusion of ICT might not only improve the outcome of current research, ${ }^{3}$ but as Jaffe, Newell and Stavins (2005: 167) explain, the value of new technology tends to increase with the number of users and such benefits associated with the overall scale of technology adoption are referred to as "dynamic increasing returns”. Hence, especially if the ICT diffusion level is already significant in the research fields, positive dynamics concerning research returns might arise due to the ICT application.

Our analysis of diffusion of ICT in environmental research sectors therefore may give some hints for policy-makers, whether the potential of ICT application for environmental R\&D sectors is sufficiently exploited and whether positive dynamics concerning research returns can be expected due to ICT application. Beyond, we aim at ascertaining and discussing the most important influence factors and contexts which could be exploited in order to optimize the positive effects of ICT use on environmental research.

The analysis is organized as follows: In Section 2, we outline the methodological approach we employ in our study, including the survey questionnaire. Thereafter, in Section 3, we present the sector-based results of our investigation and conduct a comparative analysis of these results. In Section 4, future requirements for ICT are elaborated, and finally, Section 5 provides a critical discussion of the results in view of the context of the paper as well as a short outlook.

\footnotetext{
${ }^{2}$ Røpke (2001: 419) stresses the role of information technology as "a core technology constituting a strong technological push and influencing a large number of products. Both new processes and completely new functions are introduced, and a major cluster of related technologies is developed.”

${ }^{3}$ However, according to Fuchs (2008: 306), on the one hand ICTs can foster a higher publication rate and speed in science and on the other hand may - due to the rising publication speed - have a negative influence on quality standards.
} 


\section{METHODOLOGICAL FRAMEWORK}

The analysis of Information and Communication Technologies tools (ICT) is built on a combination of four different methodological approaches identifying different level of analysis: web-based research, analysis of research activities on the field, focus groups, oneon-one interviews, and survey-based questionnaire. The definition of ICT used in the survey is "any communication device or system, including computer and networking hardware and software, mobile phones, satellite systems, control systems and sensors, information systems and software statistics (e.g. databases, model simulation, etc), Geographic Information Systems (GIS), and all other services and applications associated with them (e.g. internet services, data processing)". ${ }^{4}$

The framework comprises the analysis of the four sectors, namely climate change, biodiversity, energy efficiency and natural resources. Each sector has been investigated in order to identify its main research macro-areas, select the research sub-areas within each macro-area, and identify some key topics within each sector to prioritize future ICT research requirements. The framework is built on the findings of Labelle et al. (2008) who provides a survey of ICT applications for e-Environment. ${ }^{5}$

The initial phase involved a web-based search on the use of ICT tools and methods in different settings of environmental research. In a second step, research activities of specific institutions and universities have been investigated and studied in order to identify research areas and fields in each environmental sector, key tasks, and priorities for ICT development in the future. The information obtained in these two preliminary phases have been used to design focus groups, completed by one-on-one interviews, having the purpose of elaborating more in depth on the use of specific ICT instruments and their extent of application, as well as to pre-test the final questionnaire. People involved in the focus groups activities included researchers, $\mathrm{PhD}$ students, professors and experts in the four mentioned research sectors.

Based on the results of this analysis and building on the focus groups' activities, four questionnaires have been designed (one for each sector) focusing on use and requirements for

\footnotetext{
${ }^{4}$ Adapted from Labelle et al., 2008.

${ }^{5}$ Labelle et al. (2008) specify that e-Environment includes "the use and promotion of ICTs as an instrument for environmental protection and the sustainable use of natural resources, the initiation of actions and implementation of projects and programs for sustainable production and consumption and the environmentally safe disposal and recycling of discarded hardware and components used in ICTs, and the establishment of monitoring systems, using ICTs, to forecast and monitor the impact of natural and man-made disasters particularly in developing countries, and small economies" (Geneva Plan of Action, 2003 - World Summit on the Information Society (WSIS) Action Line C7 http://www.itu.int/wsis/docs/geneva/official/poa.html\#c7-20).
} 
ICT. More specifically, the questionnaires aim at analysing the concrete use of some ICT tools, their perceived usefulness, accessibility, limitations and problems, opportunities for future development of ICT, and perceived relevance in terms of scientific, economic and political exploitation.

\subsection{CONFIGURATION OF RESEARCH SECTORS}

The sectoral analysis identified five main macro-areas of research, common to all the fours sectors: observation and monitoring; modelling and simulation; socio-economic analysis; policy analysis and planning; and capacity building and cooperation (Fig. 1).

\section{MACRO AREA}
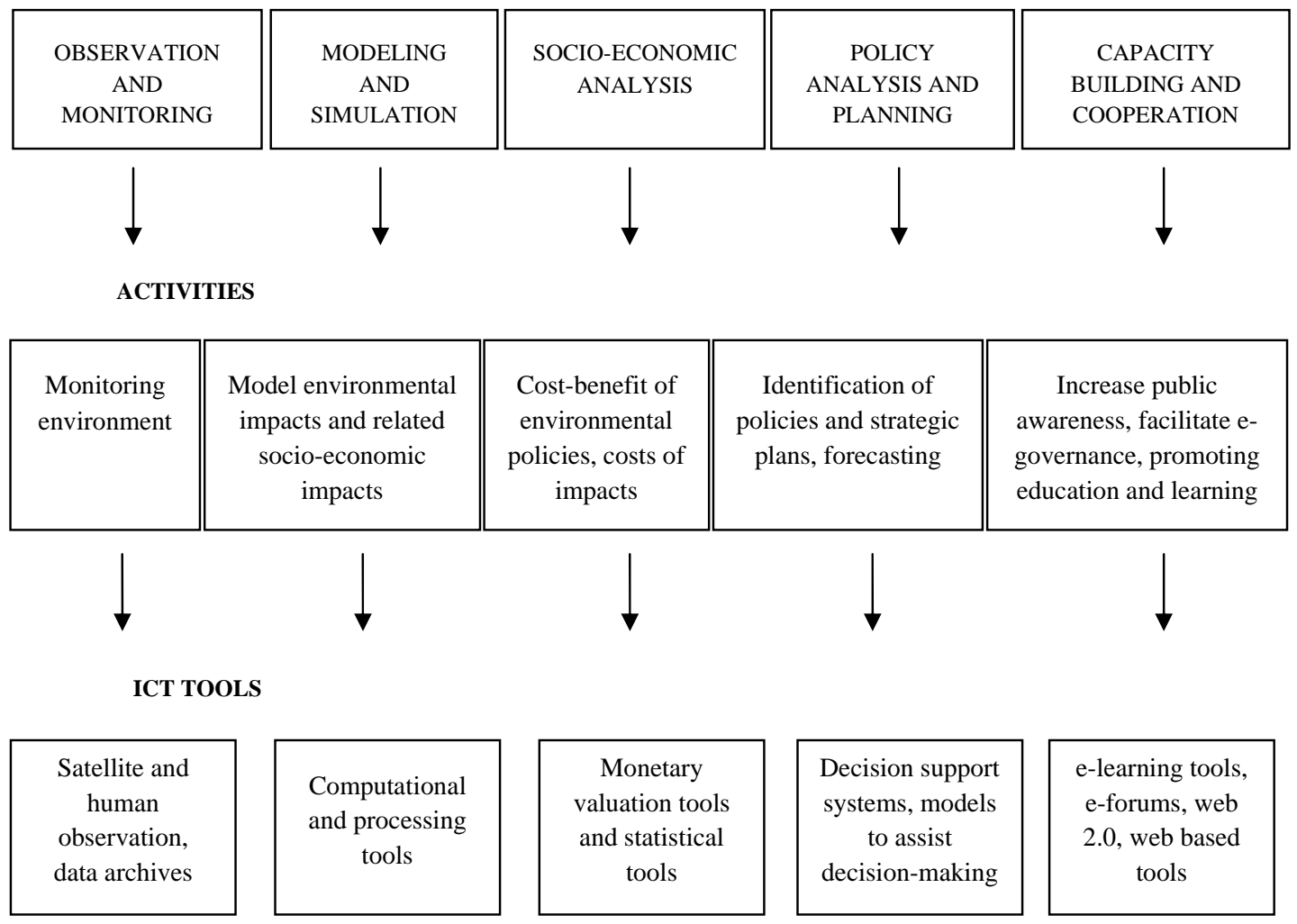

Figure 1. Macro-areas of environmental research with ICT applications.

Observation and monitoring includes research dealing with data collection and recording systems which are used to monitor the environment, to record data within geographical contexts and with different temporal coverage. ICT tools used in this area include control systems, sensors, monitoring systems, satellite technologies, geographic information systems, 
and telecommunication networks, just to name a few. Modeling and simulation refers to computational and processing tools used to model environmental impacts and subsequent socio-economic impacts. Environmental modeling usually processes data collected in the observation area to understand and simulate impacts relating to natural resources, climate change and biodiversity. Examples of ICT tools in this area include algorithms for simulation, database management systems, GIS tools, bio-physical models, socio-economic models and integrated assessment models IAM. Socio-economic research embraces tools for estimating costs and benefits associated with different environmental policies, damages related to climate change, biodiversity loss and depletion of natural resources. The scope includes specific statistical tools for monetary valuation, data processing and simulations. The tools in this area are based on micro-economic analyses, while those used for modeling the socio-economic impacts in the previous area are based on macro-economic simulation models. Policy analysis includes planning at different geographical levels (international, national and regional) and uses the data and results from the first three areas to inform decision-making and management, to formulate policies and strategic plans, to perform risk assessment, and to put in place forecasting systems. ICT tools include decision support systems, database management systems, GIS, models to assist decision-making, mapping systems, internet and networks on the web to share best practices. Finally, the capacity building and cooperation area includes efforts to increase public awareness of the need to protect the environment, to prevent depletion of natural resources, to facilitate participation in decision-making processes, and to promote education and learning. ICT in this area includes e-learning tools, online learning and capacity-building applications for developing countries, access to relevant knowledge at local level, and e-governance systems.

Each of these macro-areas is structured in a number of sub-areas, which are specific to the sector under consideration. The user profile has been analyzed in relation to the specific subareas where he is actually working. In the climate change sector, to make a concrete example, the observation area is structured into climatology, cryosphere, land use and agriculture, risk and hazards, seal level rise and other global phenomena, hydrology and water resources management. The modeling area includes climate systems and greenhouse gases emissions, catchment and regional hydrology, coupled physical processes and socio-economic impacts, among the most important. The socio-economic analysis refers to cost estimation of market and non-market damages, costs and benefits of adaptation and mitigation, and socially contingent effects (e.g. equity). Policy analysis and planning is comprised of scenario 
building and planning tools, analysis of adaptation and mitigation policies, communication policies, and international agreements. Capacity building and cooperation, finally, includes analysis of participatory tools (e-governance), learning programs and education and research/academic networking, among others.

\subsection{THE QUESTIONNAIRE}

The questionnaire structure is identical for the four sectors under analysis, being sub-divided into five main sections, after suitable adaptation of the questions to the specific context of the sector.

The first section identifies the research sub-areas in each of the five macro-areas where the respondent is actually working. These sub-areas vary according to the sector under analysis, and they represent concrete research areas at an operational level (see the example in the climate change sector in the previous section).

The second section has four main questions that analyse the use of ICT tools and how this links to the macro-areas where the respondent works. A list of ICT tools and instruments is presented to the respondent who is first asked to identify, from this general list, the tools commonly used in his research activities, and then to indicate to which specific macro-area they refer (observation, modelling, socio-economic analysis, policy analysis, capacity building). ${ }^{6}$ This question allows us to link the use of ICT tools to the five identified macroareas and to compare sectors and research areas. The respondent identifies also the main limitations and problems in using these tools, together with the potential these might have for future research. Finally, for each identified ICT tool, the respondent is asked to indicate the open-access of the tool and its usefulness using a likert scale based on five scores (where 1=high, 3=medium and 5=low).

The third section seeks to analyze the importance of ICT tools in terms of their scientific, economic and political relevance. The respondent is asked to assign a priority on a five score likert scale (where $1=$ high, $3=$ medium and $5=$ low) to each context. Scientific relevance is analysed in terms of improved multidisciplinary research, increased exchange in the scientific community, and increased access to sophisticated analysis by user-friendly tools. The economic relevance is analysed in terms of decreased research costs, opportunities to transfer

${ }^{6}$ The ICT tools included in the list have been identified in a previous stage of the ICT-ENSURE project. For more information see the webpage http://www.ict-ensure.eu 
the tools to a business context, and e-learning processes. The political relevance is set in the contexts of interfaces with policy-makers, stakeholders' participation in the decision-making process, and increased citizens' awareness. The final results for each sector are compared to reveal the relevance of ICT tools in each context, in order to provide input that may prioritize research funding.

The fourth section of the questionnaire addresses future requirements for ICT. For this purpose, a number of key features are identified and selected for each sector. Respondents are asked to indicate the priority level taking into account that the objective is to prioritize research funding in those areas. Five levels of priorities are selected using a likert scale (where $1=$ high, $3=$ medium and 5=low).

The last section includes socio-demographic questions about age, country of residence, professional position, degree, and type of organization where the respondent works. These questions are included to understand the sample composition and the respondent's profile.

\subsection{THE SAMPLE}

The questionnaire was created online and administered in the period December 2009 January 2010. For the biodiversity and energy efficiency sectors, a number of national, international and European experts were contacted, while for the climate change and natural resources sectors, the experts came from European countries only. The response rate was quite high in the energy and natural resources sectors. More specifically, we registered a 50\% response rate in the energy sector (with 39 filled questionnaires out of 75 experts contacted in total), and a $76 \%$ in the natural resources (with 38 filled questionnaires out of 50 invitations sent). In the other two sectors the response rate was much lower, but the number of contacted experts was in contrast particularly high. In the climate change sector, 240 experts have been contacted and 38 questionnaires were completed with a response rate of $15 \%$. In the biodiversity sector, the total number of contacts was 500 out of which 59 questionnaires were received. The whole sample includes a total number of 174 questionnaires completed on which the analysis has been performed.

As regards the profile of the respondents, the sample comprises a balanced distribution of professors, post-doc researchers, $\mathrm{PhD}$ students, research assistants, heads of department and scientific officers. All age groups are represented, with a lower percent in the group 60-69. The disciplinary backgrounds include, among others, environmental science, ecological 
science, economics, hydrology, geography, physical science, biology, geology, computer sciences, agronomy, engineering, all of them represented, even if with very small numbers.

For all the sectors, we cannot argue that the user profile is representing the overall public of researchers, as the sample is quite small compared with the existing scientific community. We cannot therefore link the results of the survey to the socio-demographic characteristics of the respondents.

\section{COMPARATIVE ANALYSIS AMONG SECTORS}

\subsection{RESPONDENTS’ KEY RESEARCH AREA}

The first question identifies the areas in which the respondent works. Results are reported by the number of choices made by each respondent in each macro- and sub-area (Fig. 2), taking into account that multiple answers were possible.

The results show that all the macro-areas are mostly well represented in these surveys, with some exception for the biodiversity sector where the socio-economic and policy analysis are somewhat under-represented. On the one hand, the sample does not represent the full spectrum of expertise within each sector because it is not large enough to be representative of the whole scientific community in each sector. On the other hand, however, the fact that all the sectors are equally represented allows providing an informative and indicative analysis of the ICT use and future requirements in each sector. This is known in statistic as quota sampling, where the sample population is broken down into different categories, corresponding to the main ones of the general population, though the size of each category does not reflect the population as a whole. This strategy is valuable for unrepresentative samples or when it is difficult to undertake a stratified sample. The latter is used when the categories chosen are proportionate to the categories in the whole population. In this study, however, it was impossible to apply a stratified sample, due to the large scientific community working in these sectors worldwide. So the best strategy in this study was to use the quota sampling, which is a biased sample, but with the advantage of providing an equal representation of the research areas under analysis. In this case the results of the ICT use and future requirements can be interpreted without relating them to the proportion of respondents working in each area, independently from the fact that an area is over or under represented. Special care needs, however, to be taken in interpreting the biodiversity sector, because the results refer mainly to the areas of observation, modelling and capacity building. 


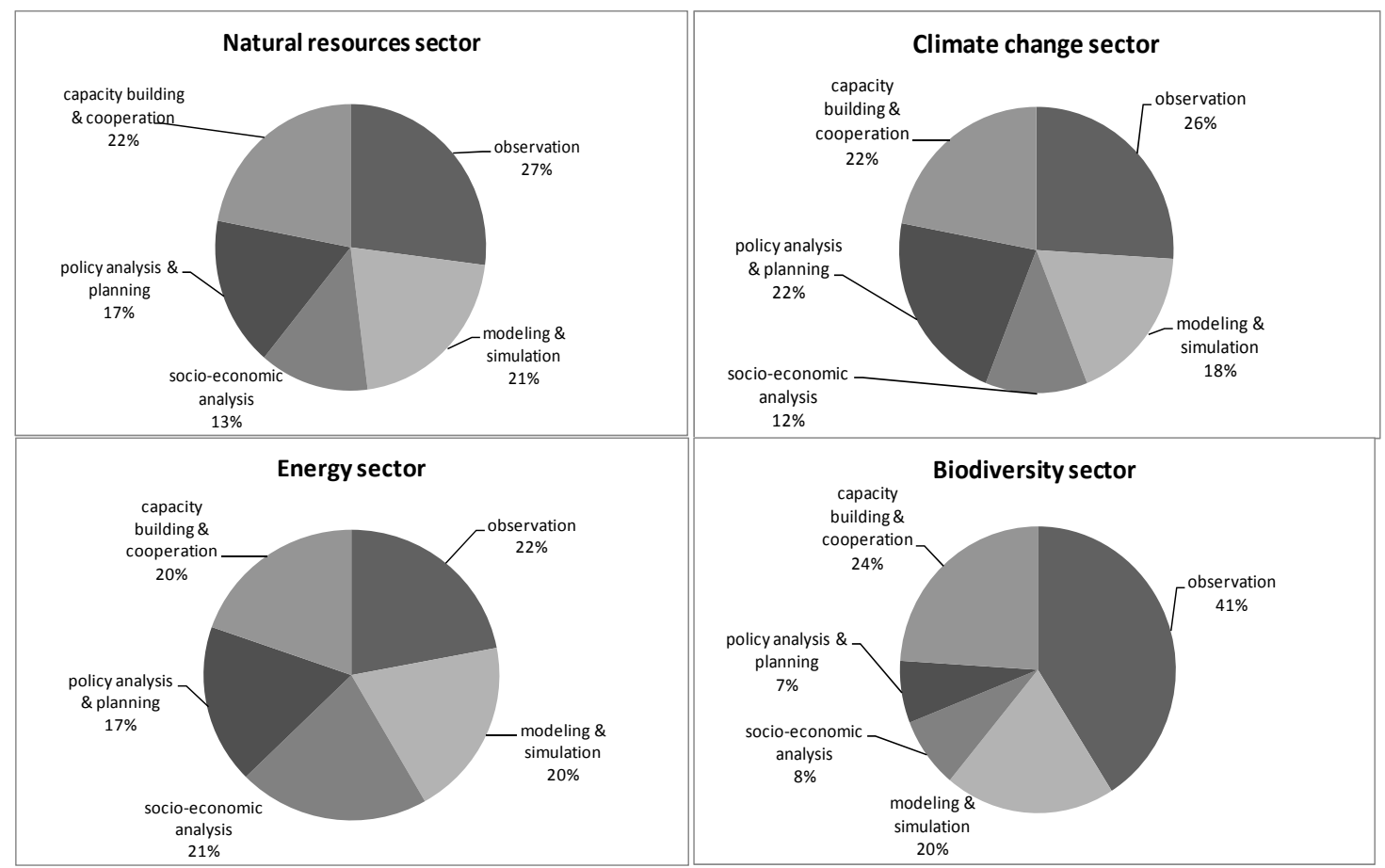

Figure 2. Research macro-area of the respondents.

\subsection{USE OF ICT TOOLS}

In the second section of the questionnaire, respondents are asked to report the ICT tools they are using in their individual research activities and to relate them with the key research macro-areas. A list of ICT tools is presented to the respondents, using the five main categories of (i) electronics and microsystems; (ii) information systems and software; (iii) media and content; (iv) communication technology and networks; and (v) others. Table 1 reports the five ICT categories. Results about the use of ICT tools can be related directly to the type of activities performed under each research areas, as these are equally represented in our sample.

Overall, the predominant group of tools used is the "information systems and software", followed by "communication technology, networks, distributed systems”. The only exception is the climate change sector for which the highest frequency of use is registered in “electronics and microsystems”, followed subsequently by “information systems”. 
"Information systems and software” includes actually a broad range of tools and instruments, as well as "communication technology", most of them being of crucial importance for research activities. These results reveal the impact of the types of research areas where the respondents are working (displayed in Table 1).

Table 1. ICT categories.

\begin{tabular}{|c|c|c|c|}
\hline $\begin{array}{l}\text { Electronics, } \\
\text { microsystems }\end{array}$ & $\begin{array}{c}\text { Information systems, } \\
\text { software }\end{array}$ & Media and content & $\begin{array}{l}\text { Communication } \\
\text { technology, networks, } \\
\text { distributed systems }\end{array}$ \\
\hline $\begin{array}{l}\text { - automation, } \\
\text { robotics } \\
\text { - control systems, } \\
\text { sensors } \\
\text { - monitoring } \\
\text { systems }\end{array}$ & $\begin{array}{l}\text { - databases, database } \\
\text { management, data } \\
\text { mining } \\
\text { - data processing / } \\
\text { data interchange } \\
\text { - simulation } \\
\text { - knowledge } \\
\text { management, } \\
\text { process management } \\
\text { - semantic } \\
\text { technologies } \\
\text { - artificial intelligence, } \\
\text { usability } \\
\text { - advanced systems } \\
\text { architecture }\end{array}$ & $\begin{array}{l}\text { - publishing, digital } \\
\text { content } \\
\text { - information filtering, } \\
\text { semantics, statistics } \\
\text { - visualisation, virtual } \\
\text { reality } \\
\text { - geographic } \\
\text { information systems } \\
\text { (GIS), location-based } \\
\text { content }\end{array}$ & $\begin{array}{l}\text { - audiovisual equipment } \\
\text { and communication } \\
\text { technology } \\
\text { - broadband technologies } \\
\text { - internet services, web } \\
\text { services, service } \\
\text { architectures } \\
\text { - mobile communications } \\
\text { - network technology, } \\
\text { network security } \\
\text { - grid computing } \\
\text { - satellite technology / } \\
\text { systems / positioning / } \\
\text { communication } \\
\text { - ubiquitous computing, } \\
\text { pervasive computing } \\
\text { - computer-supported } \\
\text { cooperation, portal } \\
\text { technologies }\end{array}$ \\
\hline
\end{tabular}

Source: ICT-ENSURE project, www.ict-ensure.eu

As exemplification of the ICT distribution among the macro-areas, we report in Fig. 3 the results for the climate change sector only, while the findings for the other sectors are reported in the Appendix (Table A1). Results show a quite balanced distribution of ICT tools among the five macro-areas, with the only exception of "electronics and microsystems" which, given the specificity of the tools, are more relevant in the observation and modelling areas. These results may confirm that research in climate change has developed quite a lot in the past decades enlarging its research objectives and aims, and implying a more balanced use of ICT tools, compared to the other sectors. The area of capacity building shows proportionally a higher percentage in the use of ICT in the climate change sector than in the other sectors. This might be explained by the strong effort registered in the last decade specifically in the 
climate change area to increase public awareness about the climatic problems and the greenhouse gas impacts.

The issues related to climate change (mitigation, adaptation strategies, impacts, etc.) are under debate constantly and have attracted also great funding to the scientific community. Not surprisingly the use of ICT in this area is more developed than in other "environmental" sectors.

The overall results seem to show that the natural resources sector tends to be more "developed" compared to the energy sector, and less "developed" compared to climate change research. There is in fact a more balanced distribution of ICT tools among research areas than in energy but still lower than the one registered in climate change (Table A1).

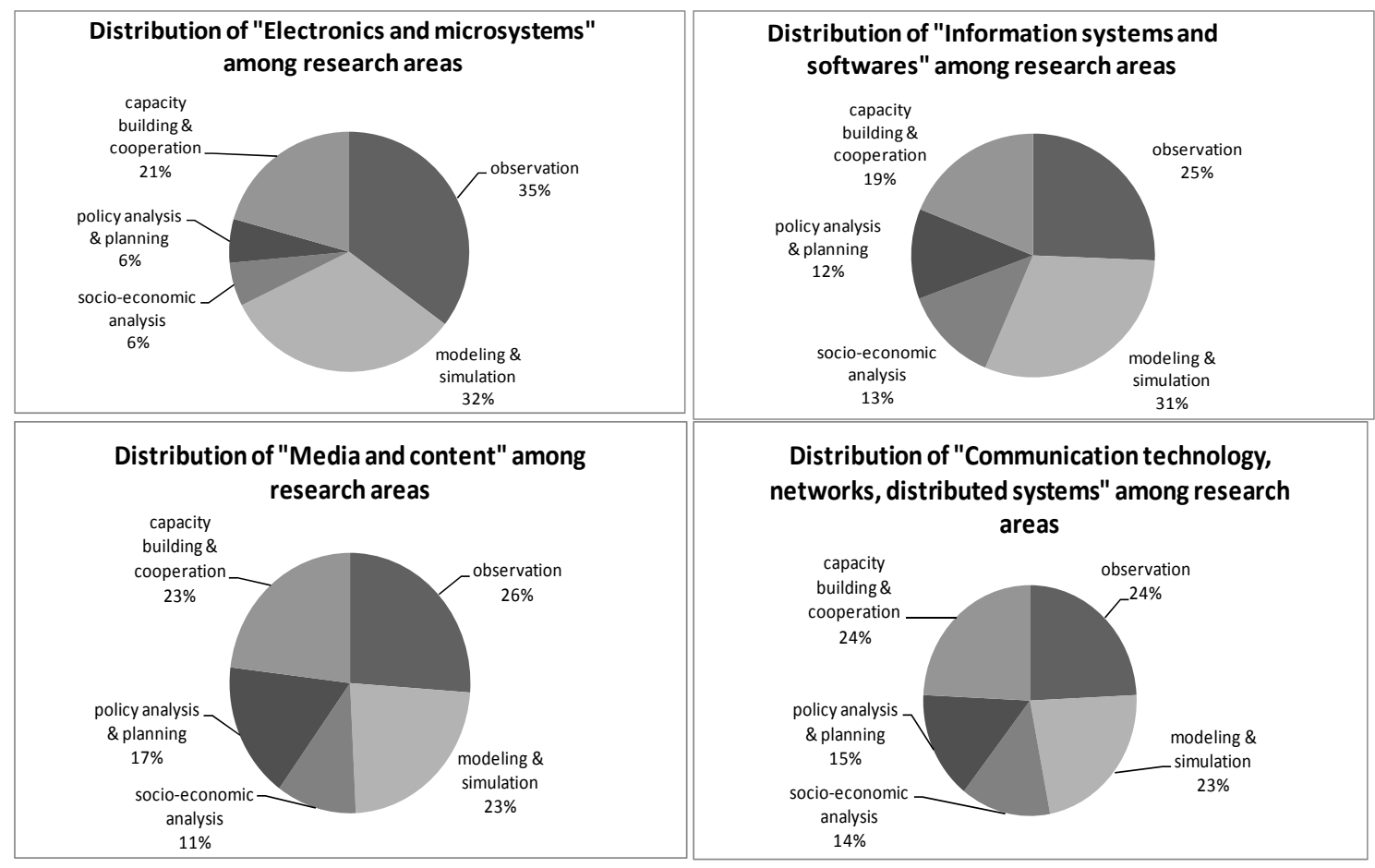

Figure 3. Use of ICT in the climate change sector, and respondents' key research area.

\subsection{SCIENTIFIC, ECONOMIC AND POLITICAL RELEVANCE OF ICT IN DIFFERENT SECTORS}

The third section of the questionnaire asks for information that would help in prioritizing contexts where ICT tools could be exploited. Three types of contexts are explored: scientific, economic and political. The first is analysed in terms of different features, namely improved 
multidisciplinary research, increased exchange in the scientific community, and increased accessibility to sophisticated analysis by user-friendly tools. The economic relevance is analysed in terms of reduction of research costs, opportunity to transfer the tool into a business context, and to education for e-learning processes. Finally, the political perspective comprises of interface with policy-makers, participation of citizens in the decision-making process, and increased public awareness of environmental impacts.

The perceived relevance of ICT tools in each context is analysed using a likert scale (with high, medium and low priority). The analysis aims at identifying the areas where ICT is judged more relevant and the relative importance of each feature. If we compare the results among the different sector (Table 2), we notice that, in all the sectors, the scientific features of ICT are always receiving the highest importance, followed by the political features and lastly the economic features.

Table 2. ICT relevance in different sectors (frequencies for high priority).

\begin{tabular}{ccccc}
\hline \multirow{2}{*}{ Features } & \multicolumn{4}{c}{ Sector } \\
\cline { 2 - 5 } & $\begin{array}{c}\text { Energy } \\
\text { efficiency }\end{array}$ & Climate change & Biodiversity & $\begin{array}{c}\text { Natural } \\
\text { resources }\end{array}$ \\
\hline Scientific & $26 \%$ & $13 \%$ & $11 \%$ & $26 \%$ \\
Economic & $12 \%$ & $5 \%$ & $7 \%$ & $13 \%$ \\
Political & $15 \%$ & $18 \%$ & $11 \%$ & $10 \%$ \\
\hline
\end{tabular}

\section{FUTURE REQUIREMENTS FOR ICT}

The fourth section of the questionnaire includes questions about prioritizing future requirements for ICT. The respondents had to provide priorities (on a likert scale with different levels of priority) by choosing from a previously defined list of requirements. The choice of these has been made in each sector by each of the sectoral experts. ${ }^{7}$ The requirements can be classified into six main categories: tools facilitating data and software accessibility and usability, GIS tools, modelling and simulation tools, tools facilitating data exchange and data sharing, e-participation tools, education and training tools.

\footnotetext{
${ }^{7}$ See Focus Area Surveys (WP8) ICT-ENSURE: Crema and Ghidini (2010), Patterson (2010), Spiteri (2010), and Strasser (2010).
} 
Accessibility and usability includes for example release of and access to data; development of standards and tools for web services and semantic tools; free and easy-to-use data capture tools, analytical tools and visualization tools; access to technical expertise/availability of hardware and open source software, etc. GIS tools relate to geo-referencing, to facilitate cadastral mapping, image processing tools, geo-referenced tools. The category of eparticipation tools makes reference to user friendly interactive tools to engage citizens, scientists and policy makers in a participatory system for decision-making. Data exchange tools and networks include the development of standards and tools for data exchange, data sharing, interactive web services and semantic tools. Modelling and simulation refer to tools for analysing economic and population changes, planning and use of natural resources. Finally, education tools are tools used for e-learning and training purposes.

Respondents' answers about future requirements in ICT are modeled using a utility function capturing the features meant to be crucial in explaining users' needs. We propose a model that relates the users' requirements for ICT to a number of explicatory variables, including the type of tool used (second section of the questionnaire), and the perceived relevance of ICT in different contexts (third section of the questionnaire). Formally, this can be expressed:

$D j=f(X i, Y i)$

where $D j$ is the priority assigned by the respondent to the ICT category $j, X i$ is a vector of the specific ICT tools effectively used by the respondent, and $Y i$ are the respondent's expectations about the relevance of ICT in the scientific, economic and political contexts.

The overall results suggest that the user requirements are driven by the use of specific ICT tools as expected, and by the scientific and political contexts where ICT is going to be developed in the near future. Economic features are found to be less important. Results are presented in Table 3. 
Table 3. Model results (OLS, dependent variable: priority assigned to ICT categories).

\begin{tabular}{|c|c|c|c|c|c|c|}
\hline & Education & $\begin{array}{l}\text { Accessibility } \\
\text { and usability }\end{array}$ & $\begin{array}{c}\text { Data } \\
\text { exchange/ } \\
\text { networks }\end{array}$ & GIS tools & $\begin{array}{c}\mathrm{e}- \\
\text { participation }\end{array}$ & $\begin{array}{l}\text { Modelling } \\
\text { and } \\
\text { simulation }\end{array}$ \\
\hline $\begin{array}{l}\text { Electronics and } \\
\text { microsystems use }\end{array}$ & $\begin{array}{c}0.051 \\
(0.047)\end{array}$ & $\begin{array}{l}0.015 \\
(0.06)\end{array}$ & $\begin{array}{c}0.007 \\
(0.045)\end{array}$ & $\begin{array}{c}0.04 \\
(0.038)\end{array}$ & $\begin{array}{l}-0.0003 \\
(0.042)\end{array}$ & $\begin{array}{l}0.094 * * \\
(0.045)\end{array}$ \\
\hline $\begin{array}{l}\text { Information systems } \\
\text { and software use }\end{array}$ & $\begin{array}{c}-0.146^{* * *} \\
(0.056)\end{array}$ & $\begin{array}{c}0.019 \\
(0.071)\end{array}$ & $\begin{array}{c}0.028 \\
(0.054)\end{array}$ & $\begin{array}{l}-0.086^{*} \\
(0.045)\end{array}$ & $\begin{array}{c}-0.126 * * \\
(0.049)\end{array}$ & $\begin{array}{l}-0.067 \\
(0.053)\end{array}$ \\
\hline $\begin{array}{l}\text { Media and content } \\
\text { use }\end{array}$ & $\begin{array}{l}0.098 * \\
(0.054)\end{array}$ & $\begin{array}{c}0.016 \\
(0.068)\end{array}$ & $\begin{array}{l}-0.006 \\
(0.052)\end{array}$ & $\begin{array}{c}0.043 \\
(0.043)\end{array}$ & - & $\begin{array}{l}0.045 \\
(0.05)\end{array}$ \\
\hline $\begin{array}{l}\text { Communication } \\
\text { technology/networks }\end{array}$ & - & - & - & - & $\begin{array}{c}0.108 * * \\
(0.047)\end{array}$ & - \\
\hline $\begin{array}{l}\text { Exchange in } \\
\text { scientific community }\end{array}$ & $\begin{array}{c}0.096 \\
(0.059)\end{array}$ & $\begin{array}{c}0.105 \\
(0.789)\end{array}$ & $\begin{array}{c}0.164 * * * \\
(0.057)\end{array}$ & $\begin{array}{c}0.034 \\
(0.049)\end{array}$ & $\begin{array}{c}0.137 * * \\
(0.053)\end{array}$ & $\begin{array}{c}0.009 \\
(0.058)\end{array}$ \\
\hline $\begin{array}{l}\text { Multidisciplinary } \\
\text { research }\end{array}$ & $\begin{array}{l}0.236 * * * \\
(0.07)\end{array}$ & $\begin{array}{c}0.231 * * \\
(0.089)\end{array}$ & $\begin{array}{l}-0.029 \\
(0.068)\end{array}$ & $\begin{array}{l}-0.078 \\
(0.056)\end{array}$ & $\begin{array}{l}-0.068 \\
(0.061)\end{array}$ & $\begin{array}{c}0.068 \\
(0.054)\end{array}$ \\
\hline Accessibility & $\begin{array}{c}0.166^{* *} \\
(0.068)\end{array}$ & $\begin{array}{c}0.244^{* * *} \\
(0.846)\end{array}$ & $\begin{array}{c}0.282 * * * \\
(0.0654)\end{array}$ & $\begin{array}{l}0.098 * \\
(0.053)\end{array}$ & $\begin{array}{l}-0.058 \\
(0.06)\end{array}$ & $\begin{array}{l}-0.006 \\
(0.063)\end{array}$ \\
\hline $\begin{array}{l}\text { Interface with policy- } \\
\text { makers }\end{array}$ & $\begin{array}{c}-0.07 \\
(0.073)\end{array}$ & $\begin{array}{c}0.035 \\
(0.094)\end{array}$ & $\begin{array}{c}0.222 * * * \\
(0.071)\end{array}$ & $\begin{array}{l}-0.057 \\
(0.059)\end{array}$ & $\begin{array}{l}-0.066 \\
(0.065)\end{array}$ & $\begin{array}{c}0.183^{* * *} \\
(0.069)\end{array}$ \\
\hline $\begin{array}{l}\text { Participation to } \\
\text { decision making }\end{array}$ & $\begin{array}{l}0.224 * * \\
(0.094)\end{array}$ & $\begin{array}{l}0.214^{*} \\
(0.125)\end{array}$ & $\begin{array}{l}-0.107 \\
(0.09)\end{array}$ & $\begin{array}{c}0.367 * * * \\
(0.078)\end{array}$ & $\begin{array}{c}0.552^{* * *} \\
(0.083)\end{array}$ & $\begin{array}{c}0.132 \\
(0.092)\end{array}$ \\
\hline Public awareness & $\begin{array}{l}0.117 * \\
(0.065)\end{array}$ & $\begin{array}{l}0.0217 \\
(0.083)\end{array}$ & $\begin{array}{l}-0.068 \\
(0.062)\end{array}$ & $\begin{array}{l}0.125 * * \\
(0.052)\end{array}$ & $\begin{array}{c}0.164^{* * *} \\
(0.058)\end{array}$ & $\begin{array}{c}0.079 \\
(0.061)\end{array}$ \\
\hline Costs & - & $\begin{array}{l}-0.142 \\
(0.099)\end{array}$ & - & $\begin{array}{l}-0.11^{*} \\
(0.062)\end{array}$ & - & $\begin{array}{c}0.307 * * * \\
(0.073)\end{array}$ \\
\hline Business context & $\begin{array}{l}-0.046 \\
(0.093)\end{array}$ & $\begin{array}{c}0.003 \\
(0.115)\end{array}$ & $\begin{array}{c}0.101 \\
(0.089)\end{array}$ & $\begin{array}{c}0.227 * * * \\
(0.072)\end{array}$ & $\begin{array}{l}-0.008 \\
(0.083)\end{array}$ & $\begin{array}{l}0.161^{*} \\
(0.085)\end{array}$ \\
\hline $\begin{array}{l}\text { Education and e- } \\
\text { learning }\end{array}$ & $\begin{array}{c}0.045 \\
(0.089)\end{array}$ & - & $\begin{array}{c}0.087 \\
(0.086)\end{array}$ & - & $\begin{array}{c}0.111 \\
(0.078)\end{array}$ & - \\
\hline Constant & $\begin{array}{c}0.028 \\
(0.035) \\
\end{array}$ & $\begin{array}{c}0.029 \\
(0.045) \\
\end{array}$ & $\begin{array}{l}-0.017 \\
(0.034)\end{array}$ & $\begin{array}{c}0.025 \\
(0.028)\end{array}$ & $\begin{array}{c}0.034 \\
(0.031) \\
\end{array}$ & $\begin{array}{c}0.002 \\
(0.033) \\
\end{array}$ \\
\hline Observations & 172 & 172 & 172 & 172 & 172 & 172 \\
\hline $\mathrm{R}^{2}$ & 0.4269 & 0.2965 & 0.4139 & 0.4393 & 0.5022 & 0.5049 \\
\hline
\end{tabular}

Notes: ${ }^{* * *} \mathrm{p}<0.01,{ }^{* *} \mathrm{p}<0.05,{ }^{*} \mathrm{p}<0.1$. Standard errors in parenthesis.

The development of educational tools is significantly related to the use of specific ICT instruments, as well as to the scientific and policy contexts where they could be developed. 
More specifically, the priority assigned to educational tools is higher among the respondents using tools related to media and content (which include GIS systems, visualization tools, information filtering, semantics, statistics, publishing and digital content) and lower among those using information systems (knowledge management, data processing and interchange, simulation, data mining, advanced systems architecture). Additionally, the priority assigned to education tools is significantly and positively related with improved multidisciplinary research and increased accessibility to sophisticated tools (scientific features), and with the possibility of improving participation to decision making and increasing public awareness about environmental problems. Economic features, such as the possibility of saving costs or using the tool in business or economic contexts, are not significant.

Requirements for accessibility and usability of data are mainly related to the scientific and policy features, like educational tools. In the policy context specifically, results show that accessibility and usability can promote the development of participatory processes, as the easy access to data and higher usability is of crucial importance for stakeholders to participate to local decision-making.

Scientific and policy features are playing the major role also for data exchange and networks. Within the scientific features, the key factors influencing the development of data exchange and networks include the possibility of expanding exchange in scientific community and improved accessibility to data. Within the policy features, the opportunity to enhance interface with policy makers represents a key factor as they may benefit from wider established scientific networks and improved data exchange between networks.

Development of GIS tools is significantly and negatively related to the use of information systems (knowledge management, data processing and interchange, simulation, data mining, advanced systems architecture). Instead, improved accessibility to data is influencing positively the priority assigned to GIS, as well as the possibility of incorporating it into participation processes through stakeholder analysis, and increasing public awareness about the use of environmental resources. Economic features are judged to be relevant for GIS requirements. In particular, there is positive relation with the possibility to transfer the tool into a business context, while there is a negative relation with research costs (the higher the importance given to the reduction of research costs, the lower the priority assigned to this tool). 
As regards e-participation tools, these are significantly and negatively related with the use of information systems and positively related with the use of communication technologies (internet services, web 2.0, mobile communications, broadband technologies, audiovisual equipment, network technology and security, grid computing, computer-supported cooperation, etc.). As expected, communication technologies have a direct influence on the development of e-participation tools, while information systems are irrelevant in this context. Secondly, the development of e-participation tools is driven by scientific features, such as the possibility of improving exchange in scientific community, and by policy features in order to promote stakeholders' involvement in decision making and diffusion of information for public awareness. Actually, e-participation tools can be used not only in policy contexts but also in the scientific domain creating for example scientific forums and exchange of data and information in the research community.

Finally, the priority assigned to modeling and simulation tools is higher among researchers using electronic tools and microsystems (automation, robotics, control and monitoring systems, sensors), in accordance with our expectations. It is interesting to see that the development of these tools is linked with policy features and in particular as an opportunity to build an interface with policy makers, which has been given special attention in the climate change sector in the last decade. This area has been in fact strongly promoted in order influence the policy arena and to increase public awareness about climatic impacts. Economic features play also a crucial role for these tools, as the possibility of reducing research costs (when tool is developed within an institution and freely accessible), and the possibility of transferring the tool to a business context. These results do not indicate that the scientific features are not important for modeling and simulation tools, but that there is a shift from the more scientific aspects (already achieved) to the policy and economic ones, which might be interpreted as a sign of "maturity" of these tools. 


\section{CONCLUSIONS AND RECOMMENDATIONS}

The individual effects of ICT on the environment are "often dependent on a wide range of variables, many of which may be hard to predict” (Rejeski 2002: 2). This holds the more because "[t]echnological change, industrial sectoral change and global environmental change have been intimately connected, even if their dynamics had different drivers” (Green et al. 2002: 79). Since the variables influencing the individual effects of ICT on the environment are an issue which is yet poorly understood, also the overall effect of ICT on sustainable development remains ambiguous and provides much scope for research. A trade-off is associated with the use of ICT as potentially significant environmental benefits are opposed to potentially significant environmental cost. As Barratt (2006: 915) remarks, increasing the use of the internet provides new opportunities, e.g., for reducing distances, sharing of knowledge and experience; and Toffel and Horvath (2004) ascertain that wireless teleconferencing results in 1-3 orders of magnitude lower emissions of $\mathrm{CO}_{2}, \mathrm{NO}_{\mathrm{X}}$ and $\mathrm{SO}_{2}$ than business travel. Yet Fichter (2003), who investigates the area of e-commerce, points out that e-commerce tends to be inherently neither environment friendly nor environment hostile. And Forge (2007) points to the unsustainability of many ICT trends, e.g. power consumption in data centres.

In order to systematize the analysis of the environmental impacts of ICT, Berkhout and Hertin (2001) distinguished between positive and negative effects of different orders. As they stress, there is little empirical evidence whether the potential of ICT to generate positive effects is indeed exploited. In our study we contribute to overcome this empirical shortcoming by conducting empirical research which mainly focuses on the first order positive impacts (“ICT for environmental protection purposes”) of ICT. More specifically, we investigate to which extent and in which way ICT is employed in environmental research as a tool to support and develop sustainable strategies. The research sectors we consider in our survey analysis are among the most prominent ones in environmental research, i.e., climate change, biodiversity, energy efficiency, and natural resources.

The methods used for this analysis include web-based research, analysis of research activities on the field, focus groups, one-on-one interviews, and survey-based questionnaires. The survey was administered to a number of researchers, professors and experts in the four mentioned sectors, with 174 questionnaires being received. 
Analysis of the working areas of the respondents shows that all the research areas are mostly well represented in all sectors, which allows providing an informative and indicative analysis of ICT use and future requirements in each sector. The only exception is the biodiversity sector where the socio-economic and policy analyses are under-represented, and consequent results need to be interpreted with some caution.

In all sectors, the highest use is registered for "information systems and software”, followed by "communication technology, networks, distributed systems", both including a broad range of tools and instruments crucial for research. The only exception is the climate change sector for which the highest frequency of use is registered in "electronics and microsystems", which are related to the climate observation and monitoring.

Overall results suggest that ICT-related tools and activities need to be developed and implemented in specific contexts, taking into account users' needs and expectations. The effective use of specific ICT instruments is playing a crucial role in determining future requirements for ICT, as well as the choice of the context for ICT development. More specifically, the scientific and political contexts are judged to be the most important, while the economic features related to ICT, such as the possibility of reducing research costs or the transfer of tools to the business sector, are less relevant.

It is interesting to note that the possibility of using ICT tools in the policy context is considered by the respondents to be of great relevance especially for e-governance, public awareness and as an interface with policy-makers. It is influencing future requirements for ICT as well. These findings confirm the analysis done by Oates (2003), who analyzed the potential of ICT applications in participatory models in the political process, and stressed the importance of educating young people in this direction.

These findings confirm that there is a need to reduce the communication gap between environmental scientists and different stakeholder groups by means of ICT. This will support a multi-disciplinary community that can co-design new approaches needed for improving the transfer of scientific knowledge between different actor groups, including policy makers, while allowing for participation at a user level at the same time (Maurer et al. 2010: 60).

ICT methods and tools can build a bridge between the scientific community and the policy area in facilitating research links to policy, as results need a platform to be debated, analyzed and discussed before reaching a consensus. Involvement of different stakeholder at this stage 
may help in designing more informed policy actions, supported by knowledge shared in forums. On the other hand, ICT tools developed in the scientific community could be transferred into business contexts or they can help in reducing the research costs.

\section{Acknowledgement}

The study has been developed in the course of the ICT-ENSURE project (EUROPEAN ICTENVIRONMENTAL SUSTAINABILITY RESEARCH, www.ict-ensure.eu). ICT-ENSURE is financed under the grant agreement number 224017 of the European Commission's seventh framework programme, Theme 3, Information and Communication Technologies. 


\section{REFERENCES}

Arnold, G.E.; de Lange, W.J. and Blind, M.W. (2005): “The Concerted Action Harmoni-CA: Facilitating the Dialogue and Bridging the Gap between Research and the WFD Implementation,” Environmental Science \& Policy 8, 213-218.

Barratt, R.S. (2006): "Meeting Lifelong Learning Needs by Distance Teaching - Clean Technology,” Journal of Cleaner Production 14, 906-915.

Berkhout, F. and Hertin, J. (2001): Impacts of Information and Communication Technologies on Environmental Sustainability: Speculations and Evidence, Report to the OECD.

Crema, L. and Ghidini, C. (2010): Focus Area Survey (WP8): Information and Communication Technologies (ICT) in Energy Efficiency Research, Technical Report for ICT-ENSURE.

Esty, D.C. (2004): “Environmental Protection in the Information Age,” New York Law Review 79, 115-211.

Fichter, K. (2003): “E-Commerce - Sorting Out the Environmental Consequences,” Journal of Industrial Ecology 6, 25-41.

Forge, S. (2007): “Powering Down: Remedies for Unsustainable ICT,” Foresight 9, 3-21.

Fuchs, C. (2008): “The Implications of New Information and Communication Technologies for Sustainability,” Environment, Development and Sustainability 10, 291-309.

Green, K.; Shackley, S.; Dewick, P. and Miozzo, M. (2002): "Long-wave Theories of Technological Change and the Global Environment,” Global Environmental Change 12, 79-81.

Hempell, T. (2005): "Does Experience Matter? Innovations and the Productivity of Information and Communication Technologies in German Services," Economics of Innovation and New Technology 14, 277 - 303.

Jaffe, A.B.; Newell, R.G. and Stavins, R.N. (2005): “A Tale of Two Market Failures: Technology and Environmental Policy,” Ecological Economics 54, 164-174.

Labelle, R.; Ludwig, K.; Rodschat, R. and Vetter, T. (2008): ICTs for e-Environment. Guidelines for Developing Countries, with a Focus on Climate Change, ICT Applications and Cybersecurity Division, Policy and Strategies Department, ITU Telecommunication Development Sector, International Telecommunication Union (ITU), Geneva, Switzerland.

Lubchenco, J. (1998): "Entering the Century of the Environment: A New Social Contract for Science,” Science 279, 491-497.

Maurer, L.; Marsh, J. and Tochtermann, K. (2010): Limitations and Potential of Information and Communication Technologies for Environmental Sustainability, in: EnviroInfo 2010, Integration of Environmental Information in Europe, Proceedings of the 24th International Conference on Informatics for Environmental Protection, Cologne / Bonn, Germany. 
Patterson, D. (2010): Focus Area Survey (WP8): Information and Communication Technologies (ICT) in Biodiversity, Technical Report for ICT-ENSURE.

Rejeski, D. (2002): “E-Commerce, the Internet, and the Environment,” Journal of Industrial Ecology 6, 1-3.

Røpke, I. (2001): "New Technology in Everyday Life - Social Processes and Environmental Impact,” Ecological Economics 38, 403-422.

Oates, B.J. (2003): “The Potential Contribution of ICTs to the Political Process," The Electronic Journal of e-Government 1, 33-44.

Spiteri, A. (2010): Focus Area Survey (WP8): Information and Communication Technologies (ICT) in Natural Resources Management, Technical Report for ICT-ENSURE.

Strasser, U. (2010): Focus Area Survey (WP8): Information and Communication Technologies (ICT) for Climate Change, Technical Report for ICT-ENSURE.

Toffel, M.W. and Horvath, A. (2004): "Environmental Implications of Wireless Technologies: News Delivery and Business Meetings,” Environmental Science \& Technology 38, 2961-2970.

Yi, L. and Thomas, H.R. (2007): "A Review of Research on the Environmental Impact of ebusiness and ICT,” Environment International 33, 841-849. 


\section{APPENDIX}

Table A1: Distribution of ICT Use in different sectors (biodiversity, energy efficiency, natural resources).

\begin{tabular}{|c|c|c|c|}
\hline $\begin{array}{l}\text { Key research areas } \\
\text { within sectors }\end{array}$ & Biodiversity & $\begin{array}{l}\text { Energy } \\
\text { Efficiency }\end{array}$ & Natural Resources \\
\hline \multicolumn{4}{|l|}{$\begin{array}{l}\text { Electronics and } \\
\text { microsystems }\end{array}$} \\
\hline $\begin{array}{l}\text { observation } \\
\text { modeling \& simulation } \\
\text { socio-economic }\end{array}$ & $\begin{array}{c}100 \% \\
0 \%\end{array}$ & $\begin{array}{l}49 \% \\
38 \%\end{array}$ & $\begin{array}{l}50 \% \\
24 \%\end{array}$ \\
\hline $\begin{array}{l}\text { analysis } \\
\text { policy analysis \& }\end{array}$ & $0 \%$ & $7 \%$ & $9 \%$ \\
\hline $\begin{array}{l}\text { planning } \\
\text { capacity building \& }\end{array}$ & $0 \%$ & $0 \%$ & $9 \%$ \\
\hline cooperation & $0 \%$ & $7 \%$ & $9 \%$ \\
\hline \multicolumn{4}{|l|}{$\begin{array}{l}\text { Information systems } \\
\text { and software }\end{array}$} \\
\hline $\begin{array}{l}\text { observation } \\
\text { modeling \& simulation } \\
\text { socio-economic }\end{array}$ & $\begin{array}{l}54 \% \\
23 \%\end{array}$ & $\begin{array}{l}23 \% \\
39 \%\end{array}$ & $\begin{array}{l}24 \% \\
42 \%\end{array}$ \\
\hline $\begin{array}{l}\text { analysis } \\
\text { policy analysis \& }\end{array}$ & $4 \%$ & $20 \%$ & $16 \%$ \\
\hline $\begin{array}{l}\text { planning } \\
\text { capacity building \& }\end{array}$ & $10 \%$ & $12 \%$ & $12 \%$ \\
\hline cooperation & $9 \%$ & $6 \%$ & $6 \%$ \\
\hline \multicolumn{4}{|l|}{ Media and content } \\
\hline $\begin{array}{l}\text { observation } \\
\text { modeling \& simulation } \\
\text { socio-economic }\end{array}$ & $\begin{array}{l}57 \% \\
19 \%\end{array}$ & $\begin{array}{l}30 \% \\
28 \%\end{array}$ & $\begin{array}{l}25 \% \\
25 \%\end{array}$ \\
\hline $\begin{array}{l}\text { analysis } \\
\text { policy analysis \& }\end{array}$ & $5 \%$ & $16 \%$ & $16 \%$ \\
\hline $\begin{array}{l}\text { planning } \\
\text { capacity building \& }\end{array}$ & $10 \%$ & $14 \%$ & $16 \%$ \\
\hline cooperation & $9 \%$ & $12 \%$ & $18 \%$ \\
\hline \multicolumn{4}{|l|}{$\begin{array}{l}\text { Communication } \\
\text { technology, networks, } \\
\text { distributed systems }\end{array}$} \\
\hline observation & $53 \%$ & $27 \%$ & $27 \%$ \\
\hline $\begin{array}{l}\text { modeling \& simulation } \\
\text { socio-economic }\end{array}$ & $20 \%$ & $21 \%$ & $19 \%$ \\
\hline $\begin{array}{l}\text { analysis } \\
\text { policy analysis \& }\end{array}$ & $7 \%$ & $13 \%$ & $12 \%$ \\
\hline $\begin{array}{l}\text { planning } \\
\text { capacity building \& }\end{array}$ & $9 \%$ & $18 \%$ & $14 \%$ \\
\hline cooperation & $11 \%$ & $22 \%$ & $28 \%$ \\
\hline
\end{tabular}




\title{
BC3 WORKING PAPER SERIES
}

\author{
Basque Centre for Climate Change (BC3), Bilbao, Spain
}

The BC3 Working Paper Series is available on the internet at the following addresses:

http://www.bc3research.org/lits_publications.html

$\underline{\text { http://ideas.repec.org/s/bcc/wpaper.html }}$

BC3 Working Papers available (see website for full list):

2010-04

2010-05

2010-06

2010-07

2010-08

2010-09

2010-10

2010-11

2010-12

2010-13

2010-14

2010-15

2010-16

2010-17

2010-18

Giacomo Giannoccaro and Julia Martin-Ortega: Environmental Concerns in Water Pricing Policy: an Application of Data Envelopment Analysis (DEA)

Roger Fouquet: The Slow Search for Solutions: Lessons from Historical Energy Transitions by Sector and Service

Ibon Galarraga, Mikel González-Eguino and Anil Markandya: Evaluating the Role of Energy Efficiency Labels: the Case of Dish Washers

Luis M. Abadie, Mikel González-Eguino and José M. Chamorro: Optimal Abandonment of Coal-Fired Stations in the EU

Dirk Rübbelke and Stefan Vögele: Impacts of Climate Change on European Critical Infrastructures: The Case of the Power Sector

Roger Fouquet: The Sustainability of 'Sustainable' Energy Use: Historical Evidence on the Relationship between Economic Growth and Renewable Energy

Karen Pittel and Dirk Rübbelke: Energy Supply and the Sustainability of Endogenous Growth

Ramon Arigoni Ortiz, Alexander Golub, Oleg Lugovoy, Anil Markandya and James Wang: The DICER Model: Methodological Issues and Initial Results.

Elena Ojea, Julia Martin-Ortega and Aline Chiabai: Classifying Ecosystem Services for Economic Valuation: the Case of Forest Water Services

Aline Chiabai, Chiara Travisi, Anil Markandya, Helen Ding, and Paulo Nunes: Economic Assessment of Forest Ecosystem Services Losses: Cost of Policy Inaction

Kaysara Khatun: Competing Ecosystem services: an Assessment of Carbon and Timber in the Tropical Forests of Central America

Karen Pittel and Dirk Rübbelke: Local and Global Externalities, Environmental Policies and Growth

Margherita Grasso, Matteo Manera, Aline Chiabai, and Anil Markandya: The Health Effects of Climate Change: A Survey of Recent Quantitative Research

Luis Mari Abadie, Ramon Arigoni Ortiz and Ibon Galarraga: The Determinants of Energy Efficiency Investments in the U.S.

Aline Chiabai, Dirk Rübbelke and Lisa Maurer: ICT Application in the Research for Environmental Sustainability 